\title{
Ambiente mediado por computador para auxiliar alunos com necessidades especiais auditivas na aprendizagem da língua portuguesa
}

\author{
João Carlos Lopes Fernandes e Silvia Cristina Martini Rodrigues² \\ Recebido em: 07/09/2014. Aprovado em: 22/11/2014. Disponibilizado em: 26/12/2014
}

1. João Carlos Lopes Fernandes é Doutor em Engenharia Biomédica na área de Tecnologias Computacionais pela Universidade de Mogi das Cruzes (2012). Mestre em Engenharia de Computação pelo Instituto de Pesquisas Tecnológicas do Estado de São Paulo (2006). Bacharel em Ciências da Computação pela Universidade Municipal de São Caetano do Sul (1990). Atualmente é Coordenador do curso Análise e Desenvolvimento de Sistemas da Faculdade de Tecnologia de São Caetano do Sul e professor do curso de Tecnologia em Segurança, professor associado do Instituto Mauá de Tecnologia, professor e autor da pós-graduação da Unyleya, pesquisador da Faculdade Eniac, Membro da Comissão Editorial e do comitê de pareceristas Ad Hoc da Revista Augusto Guzzo e diretor técnico da JRN Consult.

2. Silvia Cristina Martini Rodrigues é doutorado e pós doutorado em Engenharia Elétrica pela Universidade de São Paulo (2004). mestrado em Engenharia Elétrica pela Universidade de São Paulo (1999) e graduada em Matemática pela Universidade Federal de São Carlos (1995). Atualmente é pesquisador e professor auxiliar nível pca-4 da Universidade de Mogi das Cruzes (UMC). Tem experiência na área de Engenharia Biomédica, com ênfase em Imagens Médicas, atuando principalmente nos seguintes temas: Ambiente Virtual para ensino e aprendizagem, Diagnóstico Auxiliado por Computador (CAD), Processamento de Imagens Médicas, Densidade Mamográfica. É Membro Titular da Sociedade Brasileira de Engenharia Biomédica (SBEB) e assessora interna do Programa de Iniciação Científica da Universidade de Mogi das Cruzes (UMC). Tem atuado como assessora ad-hoc da FAPESP, CNPq e CAPES nas áreas de informática médica e ensino de matemática.

\section{Resumo}

Existem diferenças entre a deficiência auditiva e a surdes; a deficiência auditiva é adquirida após o nascimento e a surdes é congênita, ou seja, ocorre antes do nascimento. Um surdo possui como modelo linguístico e cultural a língua de sinais, já o deficiente auditivo tenta utilizar a língua oral (o português falado e sinalizado) e na maioria das vezes rejeita a língua de sinais. De qualquer forma a dificuldade destes grupos de pessoas fica evidenciada em sua comunicação social. As escolas de educação especial no Brasil utilizam a LIBRAS (Língua Brasileira de Sinais), como método de alfabetização. Ela possui suas próprias regras e ao contrário do que muitas pessoas pensam não é o português sinalizado. Somente após a alfabetização em LIBRAS, os alunos incidam o contato com o português escrito. É como aprender uma segunda língua que possui novas regras. Desta maneira muitas dificuldades aparecem e necessitam de apoio. Como o uso do computador é evidenciado nas escolas os pesquisadores criaram um ambiente virtual de aprendizagem para tentar reduzir estas dificuldades na aprendizagem da língua portuguesa e permitir sua intersecção com a LIBRAS. Este ambiente foi desenvolvido na tese de doutorado realizada na UMC (universidade de Mogi das Cruzes).

Palavras-chave: Mediado por computador, aprendizagem, português, LIBRAS. 


\begin{abstract}
There are differences between the hearing loss and the deafness; bearing impairment is acquired after birth and the deafness is congenital, i.e. occurs before birth. A deaf has as language model and cultural language of signs, already the hearing impaired tries to use the oral language (spoken English and flagged) and most of the times rejects the language of signs. In any case, the difficulty of these groups of people is evidenced in their media. The special education schools in Brazil use LIBRAS (Brazilian Sign Language), as a method of literacy. It has its own rules and contrary to what many people think it is not the Portuguese flagged. Only after the literacy in LIBRAS, the students relating to contact with the English writing. It is like learning a second language that has new rules. In this way many difficulties appear and need support. As the use of the computer is evidenced in schools the researchers created a virtual learning environment to try to reduce these difficulties in learning the Portuguese language and allow its intersection with the LIBRAS. This environment has been developed in my doctoral thesis held in UMC (Universidade de Mogi das Cruzes).
\end{abstract}

Keywords: Mediated by computer, learning, Portuguese, LIBRAS. 


\section{Introdução}

O objetivo deste estudo é demonstrar que atualmente o uso da computação no apoio educacional, já é uma realidade. Ele auxilia não apenas os estudantes comuns no cotidiano, mas após os anos $70 \mathrm{com}$ a revolução tecnológica se tornou uma ferramenta imprescindível para os alunos portadores de necessidades especiais. Esta pesquisa se foca no desenvolvimento de estratégias de comunicação para deficientes auditivos com auxilio da tecnologia na deficiência auditiva e a surdes. É importante destacar que a deficiência auditiva é adquirida após o nascimento e a surdes é congênita, ou seja, ocorre antes do nascimento.

Existem varias opções, como o uso de jogos, sites educacionais e ambientes para aprendizagem. A metodologia utilizada é o desenvolvimento e a criação de ambiente virtual de aprendizagem para auxiliar os surdos em suas dificuldades com a língua portuguesa escrita. A justificativa para a criação deste ambiente se dá a partir da observação da intersecção da LIBRAS, como forma de aprendizagem da língua portuguesa escrita. Neste método serão utilizados recursos tecnológicos como imagens e vídeos em LIBRAS buscando aproximar o deficiente auditivo de situações de seu cotidiano.

Conforme Levy (1996), um ambiente virtual de aprendizagem nunca poderá ir contra o real; ele deverá ser uma interface para aplicações computacionais, onde o usuário poderá interagir, em tempo real, utilizando-se dos dispositivos de entrada, como teclado, mouse entre outros.

A hipótese é que essas estratégias possam ser apresentadas como informações de uma forma mais fácil para pessoas que têm problemas em assimilar um determinado conteúdo, como por exemplo, a língua portuguesa utilizando recursos téoricos de Levy (1996); [1]

\section{O cotidiano do surdo}

O mercado atual já oferece algumas soluções voltadas aos surdos, na figura 1 é apresentado um telefone e dois modelos de relógio que foram desenvolvidos para a comunidade surda e são utilizados em seu cotidiano.
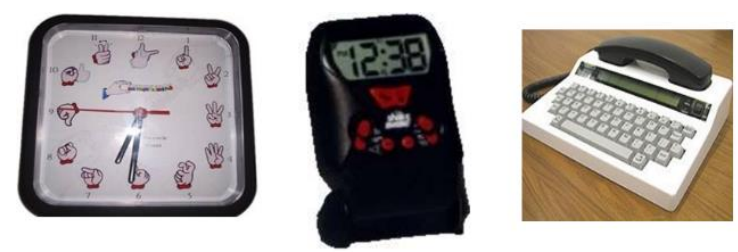

Figura 1: Soluções para o cotidiano de um surdo

\section{A Literatura Voltada ao Surdo}

As editoras produzem livros específicos à comunidade surda, a figura 2, ilustra três opções que já se encontram a venda.

$\mathrm{Na}$ literatura surda todos os livros analisados possuem o texto em português e as transcrições para a língua de sinais, na verdade ficam como uma tradução e como os alunos já são alfabetizados em LIBRAS a maioria não lê o português, a utilização destes livros deve ser mediada por professores especialistas em LIBRAS. 

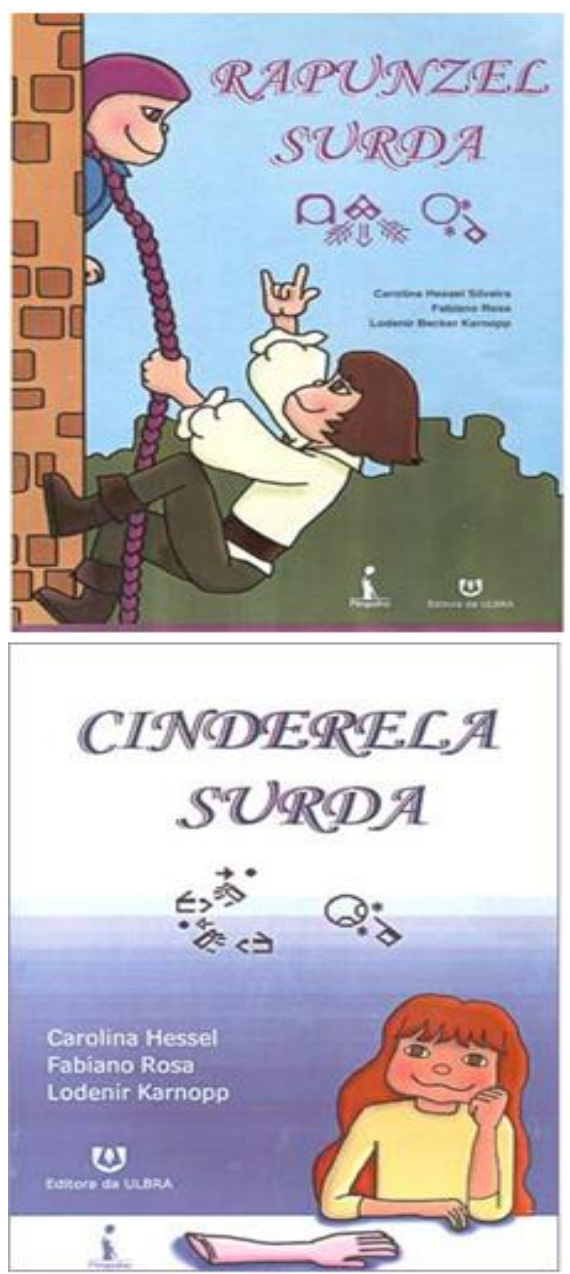

Figura 2: Literatura surda Fonte: produzido pelos autores (10/2014).

\section{O Material Didático}

A figura 3 apresenta uma ideia de como o material didático é utilizado na alfabetização dos surdos.
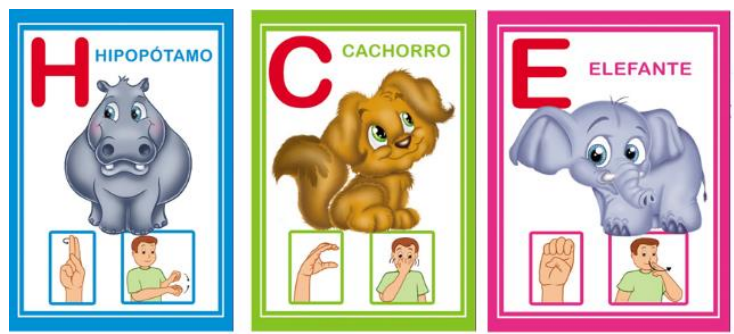

Figura 3: Materil de alfabetização para surdos Fonte: produzido pelos autores (10/2014).
Podem-se verificar na figura 3 que são utilizadas imagens, cores e sinais, este tipo de alfabe-tização é baseado na cartilha caminho suave que desde 1948 é utilizada na alfabetização de alunos (ouvintes).

Para o surdo este tipo de alfabetização é muito eficiente para LIBRAS, mas não apresenta bons resultados na formação de frases, como pode ser observado na figura 4 e 5 .

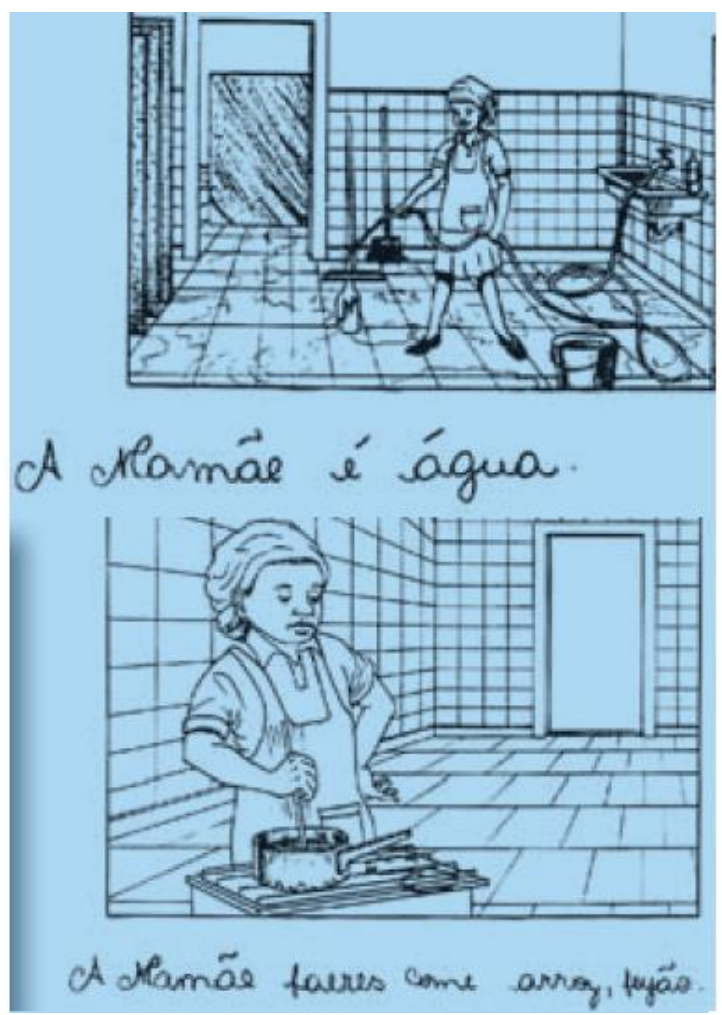

Figura 4: Frases (simples) de alunos surdos Fonte: produzido pelos autores (10/2014). 


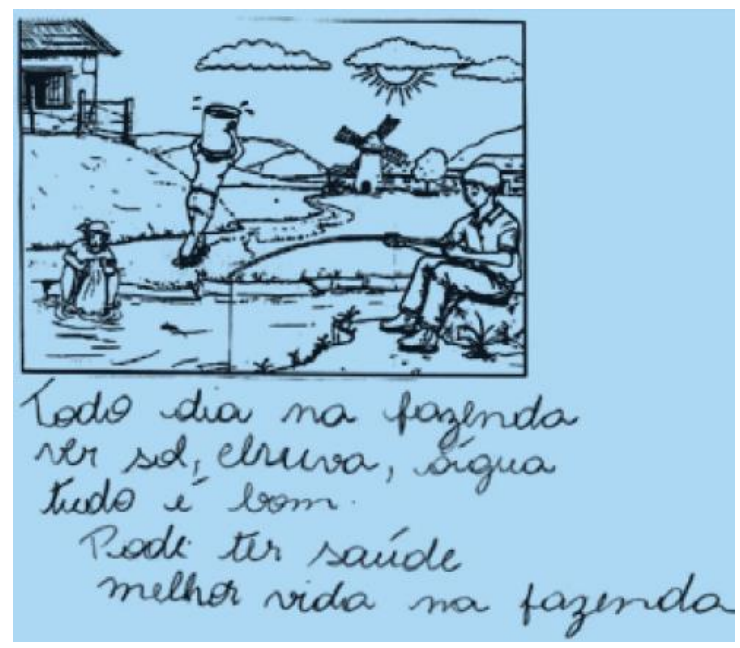

Figura 5: Frases (complexas) de alunos surdos Fonte: produzido pelos autores (10/2014).

\section{Procedimentos Educacionais}

Para o ensino de surdos existem três procedimentos ou tendências:

O Oralismo que busca integrar o surdo com os ouvintes, ele propõem o desenvolvimento da língua oral e valoriza a utilização de próteses auditivas.

A Comunicação Total que defende a utilização de todas as formas de comunicação (gestos naturais, português sinalizado, LIBRAS (Língua Brasileira de Sinais), leitura labial e escrita).

$\mathrm{O}$ Bilinguismo, que divide a alfabetização dos alunos em duas partes, neste caso o aluno é primeiro alfabetizado em uma Língua de sinais e depois como segunda língua ele aprende o idioma (língua) oficial de seu país.

\section{O Ensino de Língua Portuguesa Para Surdos}

A pesquisa realizada em uma escola de ensino especial para surdos comprovou a existência de uma grande dificuldade na utilização de tempos verbais na construção de frases, como o verifi-cado na figura 4 . O que o aluno tenta fazer é transformar a linguagem gestual em escrita, ele não se preocupa com os tempos verbais e com isso os resultados na criação e interpretações de frases são muito ruins.

Segundo o relato dos professores de língua portuguesa da instituição de ensino especial, este é um problema encontrado em toda a comunidade surda Brasileira.

Esta dificuldade é claramente observa nas relações sociais e podem afetar a vida acadêmica e profissional de um surdo.

A quantidade de surdos que completam um curso superior é muito pequena, pois a base edu-cacional não o prepara para algumas interações com pessoas ouvintes.

\section{Discussão do projeto}

Como o avanço da utilização dos recursos tecnológicos, como computadores e a Internet, e sua ótima aceitação pelos os alunos, o desenvolvimento de um ambiente virtual de aprendizagem (AVA) para auxiliar surdos na elaboração de frases, respeitando às regras gramaticais e os tempos verbais da língua portuguesa, se justificou.

Todos os ambientes estudados para servirem como apoio ao desenvolvimento, não buscam interconectar a LIBRAS com a língua portuguesa, todos aparentemente trabalhavam mais como a função de tradução.

Em 1996, o professor Doutor Antônio Carlos da Rocha Costa da PUC de Porto Alegre, iniciava a utilização do Sign Writing [2]. Este sistema serviu de ponto de partida para alguns softwares desenvolvidos para a produção de textos e exercícios da escrita da língua de sinais por alguns núcleos de pesquisa de educação e surdez no Brasil.

A Unisinos em 2002 desenvolveu o Sign Web Message, baseado no sistema Sign 
Writing, através da coordenação do professor Doutor Sérgio Crespo das Unisinos. Ele é um webmail que permite a utilização tanto da escrita da língua portuguesa quanto a utilização da LIBRAS.

O "Falibras", captura a voz humana e a transforma em texto utilizando-se do software IBM. O texto é analisado através de um interpretador que realiza sua correção ortografia e apresenta a tradução adequada em LIBRAS. [3]

Na Unicamp o professor Doutor José Mario De Martino e a Doutora Wanessa Amaral, desenvolveram um sistema utilizando computação gráfica que transformam as palavras digitadas em um computador em simbologia da LIBRAS. [4]

$\mathrm{O}$ ambiente desenvolvido auxiliou o deficiente auditivo com suas dificuldades de aprendizagem na língua portuguesa escrita, quando ele já era alfabetizado em LIBRAS.

No desenvolvimento foi utilizado à linguagem de programação Visual Basic e o banco de dados PostgreSQL. Todo o desenvolvimento e testes foram acompanhados por umas especialistas da educação par surdos.

O ambiente [5] foi dividido em fase 5 fases e os usuários devem preencher lacunas existentes entre as palavras, para isto são oferecidas opções para escolha até a quarta fase.

Antes do preenchimento da frase um vídeo com as orientações em LIBRAS é exibido e permite ser repetido quantas vezes o usuário ache necessário, após assisti-lo o usuário deverá clicar sobre a(s) palavra(s) que julgar ser a correta para completar a frase (fase 1 a 4). Caso exista alguma dúvida ele poderá a qualquer momento acionar a função "orientações" (posicionada bem abaixo da caixa onde são apresentados os vídeos) e assistir o vídeo em LIBRAS novamente.

O usuário completará outra frase de mesmo nível de complexidade até finalizar a fase, ou seja, conseguir atingir o entendimento mínimo para prosseguir fase seguinte, criando três frases corretas.

A figura 6 apresenta um exemplo de tela da primeira fase do ambiente.

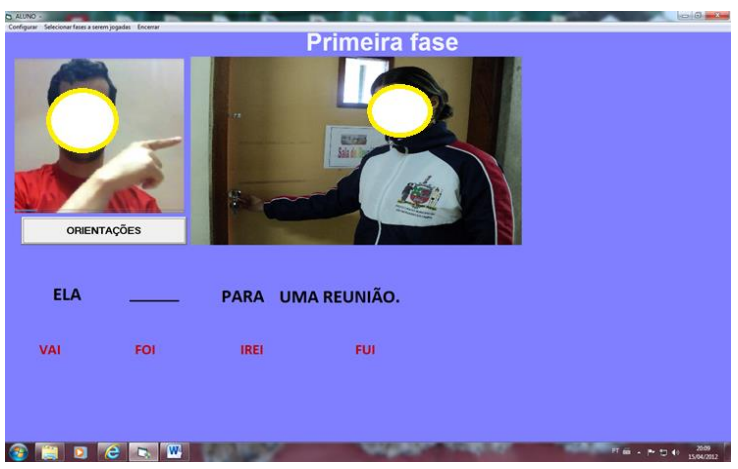

Figura 6: Primeira fase do ambiente Fonte: produzido pelos autores (10/2014).

A figura 7 ilustra a tela da quarta fase, onde se pode verificar que o nivel de difucldade e graduativo e segue as mesmas regras das fases anterios.

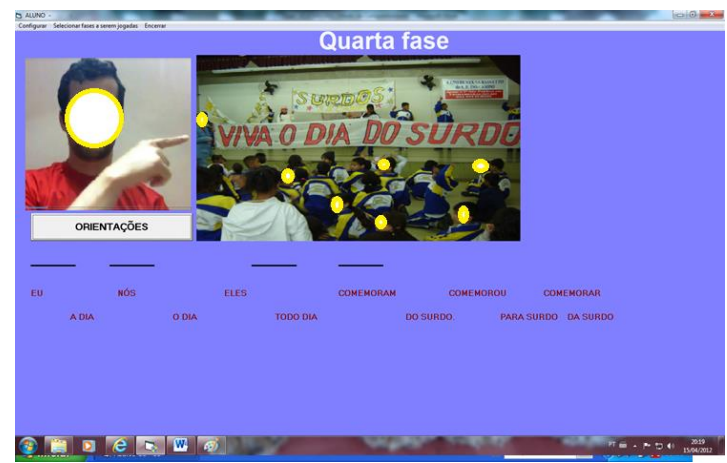

Figura 7: Quarta fase do ambiente

Fonte: produzido pelos autores (10/2014).

Para garantir que não existam tentativas de repetição, o vulgar "chute", o ambiente embaralha as palavras e modifica a posição das lacunas de forma aletoriamente. Como pode ser visto na figura 8 , no detalhe (a), do Fluxograma das Tarefas. 


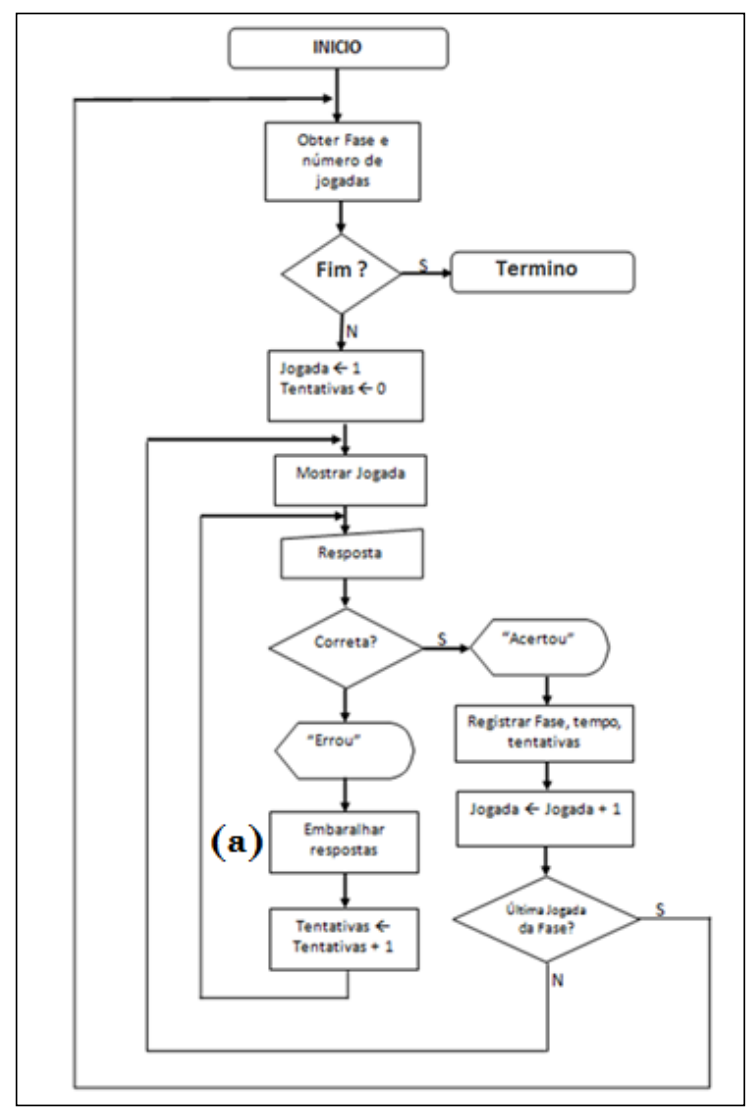

Figura 8: Fluxograma de Tarefas Fonte: produzido pelos autores (10/2014).

A quinta fase é a mais avançada nela o usuário deverá utilizar o teclado e criar uma frase sem opções de escolha, nela o sistema verifica ortografia, sintaxe e pontuação (figura 9)

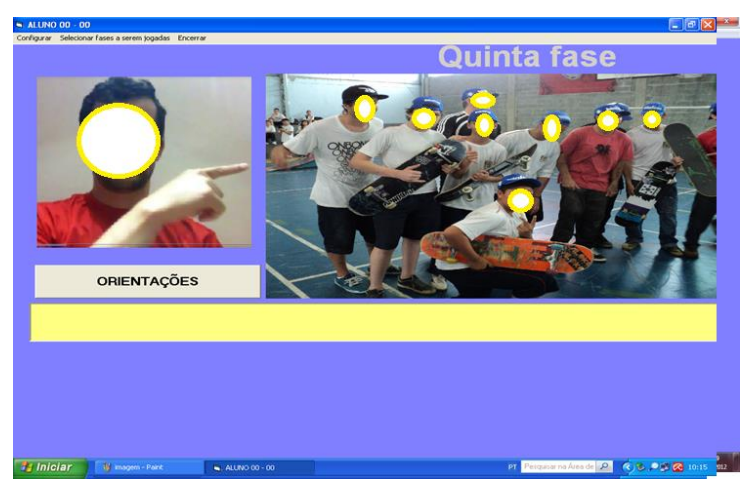

Figura 9: Quinta fase do ambiente Fonte: produzido pelos autores (10/2014).
A figura 10 apresenta a sinalização do ambiente, à expressão facial é utilizada e aproxima o aluno surdo de sua realidade.
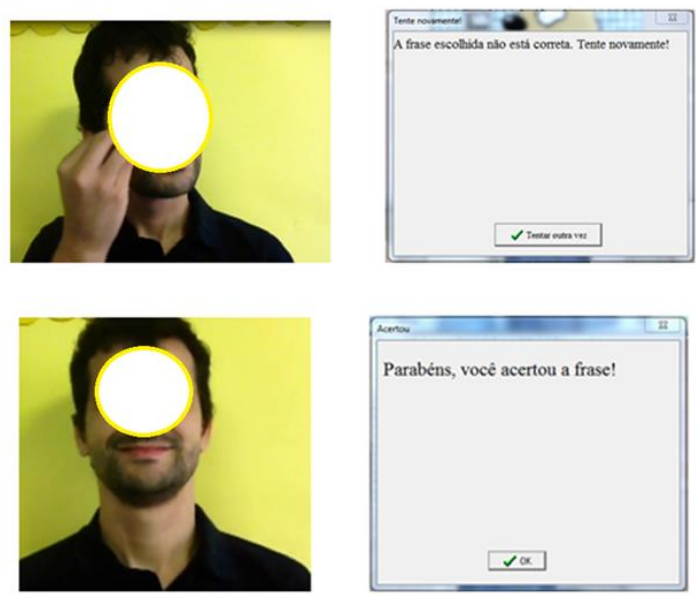

Figura 10: Sinalização

Fonte: produzido pelos autores (10/2014).

\section{Considerações Finais}

A análise dos resultados obtidos, são apresentados na figura 11 e comprovam a eficiência da ambiente, ficou evidenciada que após a utilização do ambiente o escore alcançado pelos alunos na disciplina de língua portuguesa se aproximou dos melhores resultados dos alunos que não possuíam dificuldades. (alunos selecionados pela escola).

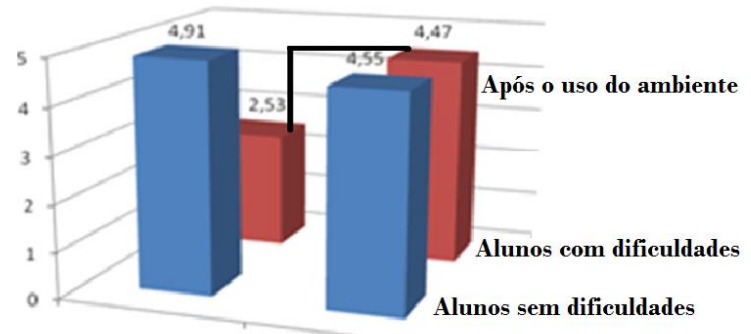

Figura 11: Tabulação de resultados [5]

Fonte: produzido pelos autores (10/2014).

A utilização de vídeos em LIBRAS e as fotos utilizadas no ambiente representam situações enfrentadas pelos surdos e facilitaram a criação das frases em língua portuguesa e sua interpretação. 
Com pequenas adaptações o ambiente desenvolvido poderá ser utilizado por outras disciplinas, e permitir a interação da aprendizagem com a LIBRAS.

Como qualquer ambiente computação serão necessária atualização que apareceram com a utilização de um maior numero de surdos

\section{Bibliografía}

[1] LEVY, P. O que é o virtual. São Paulo: Editora Trinta e Quatro, 1996.

[2].SIGN. Um capítulo da história do Sign

Writing. Disponível em <http://www.signwriting.org/library/histor y/hist010.html>. Acessado em 20. mai. 2010.

[3] CORADINE, L. C.; ALBUQUERQUE,

F. C.; SILVA, A.; MADEIRO, M.;
PEREIRA, M.: Interpretação de orações simples através do Falibras (Tradutor Português-Libras) para auxiliar na aprendizagem de crianças surdas. Novas Tecnologias na Educação, Porto Alegre, v. 5, nº 2, dez, 2007.

[4] MARTINO, J. M. D.; AMARAL, W. Comunicação estabelecida. Unicamp. Jornal da Unicamp, Campinas, 14 a 20 de maio de 2012. Edição 526. Meio eletrônico. [5] FERNANDES, J.C.L. Tese de doutorado: Ambiente virtual para auxiliar surdos na construção de frases com diferentes tempos verbais. 2012. Orientador: Silvia Cristina Martini Rodrigues. 